\title{
- Congenital absence of the pulmonary valve
}

\author{
Fergus J. Macartney ${ }^{1}$ and Graham A. H. Miller ${ }^{2}$ \\ From the Department of Cardiology, Brompton Hospital, London S.W.3
}

The clinical, radiological, electrocardiographic, and haemodynamic findings in 7 patients with the syndrome of congenital absence of the pulmonary valve with ventricular septal defect are reported. Findings included a pansystolic murmur and a low-pitched delayed diastolic murmur at the left sternal border with no pulmonary valve closure sound, an rs $R^{\prime}$ pattern in $V I$ on the electrocardiogram, and a chest $\mathrm{x}$-ray showing a large heart and gross dilatation of the main, left or right pulmonary arteries but normal or reduced vascularity of the peripheral lung fields. Cardiac catheterization showed a left-to-right shunt at ventricular level in every case, though in one the shunt was bidirectional. Despite right ventricular systolic pressures at least 75 per cent of systemic level in every patient, the pulmonary artery pressure was invariably normal. Pulmonary stenosis was shown to exist at infundibular level, at valve ring level, or at both. Selective right ventricular angiography was diagnostic: the main and right or left pulmonary arteries were aneurysmally dilated and there was an abrupt transition in calibre between these vessels and their immediate branches; enlargement of the right pulmonary artery caused distortion and downward displacement of the left atrium in 4 patients; in 2 there was a flat 'diaphragm' in the pulmonary valve position.

The diagnosis was confirmed in 3 patients by necropsy. The pulmonary valve was represented by at most a rudimentary fringe of tissue. Histological examination of the pulmonary arteries in one patient showed a correlation between the dilatation of the artery and the structure of its wall.

The syndrome of ventricular septal defect with absence of the pulmonary valve is rare, there being some 30 recorded cases (Lavenne et al., I954; Campeau, Ruble, and Cooksey, 1957; Onesti and Harned, 1958; Smith, DuShane, and Edwards, 1959; Campeau, Gil- bert, and Aerichide, 196I; Gasul et al., 196I; Miller, Lev, and Paul, 1962; Elliott, Shanklin, and Schiebler, I962; Venables, I962; D'Cruz, Lendrum, and Novak, 1964; Ruttenberg et al., 1964; Childers and McCrea, 1964; Soulié et al., 1967). Only 6 of these were studied by selective right ventricular angiography (Rut-

- tenberg et al., 1964; D’Cruz et al., 1964; Soulié et al., 1967).

We report here the clinical, haemodynamic, and angiographic findings in 7 patients (4 female, 3 male; age range 4 weeks to 13 years) with this syndrome, each studied by selective right ventricular angiography; the diagnosis was confirmed at operation or necropsy in 3.

- Received 22 January 1970.

${ }^{1}$ Present address: The Mayo Clinic, Rochester, Minnesota 55901, U.S.A.

${ }^{2}$ Requests for reprints should be addressed to Dr. G. A. H. Miller, Brompton Hospital, London S.W. 3 . 5

\section{Clinical features}

In all patients the diagnosis of congenital heart disease had been made early in life. In one patient (Case 4) there had been deep cyanosis for the first two days of life which then disappeared. None of the patients squatted or suffered from cyanotic attacks; none appeared centrally cyanosed or showed finger clubbing. Four patients (Cases $1,4,6$, and 7) had a history of recurrent chest infections and cardiac failure in infancy, and these patients tended to have the largest left-toright shunts. In one, there was a history suggestive of bronchial compression in infancy (Miller et al., 1962) though this was not proven. All suffered exertional dyspnoea.

Physical examination revealed children all below the Ioth percentile with respect to weight and the 25th percentile with respect to height. The arterial pulses were normal in every patient. The praecordium was overactive in every patient. All of the patients subsequently shown to have left-to-right shunts had pansystolic murmurs and thrills maximal in the third or fourth interspace at the left sternal edge. In contrast, Case 5, with a right- 
TABLE

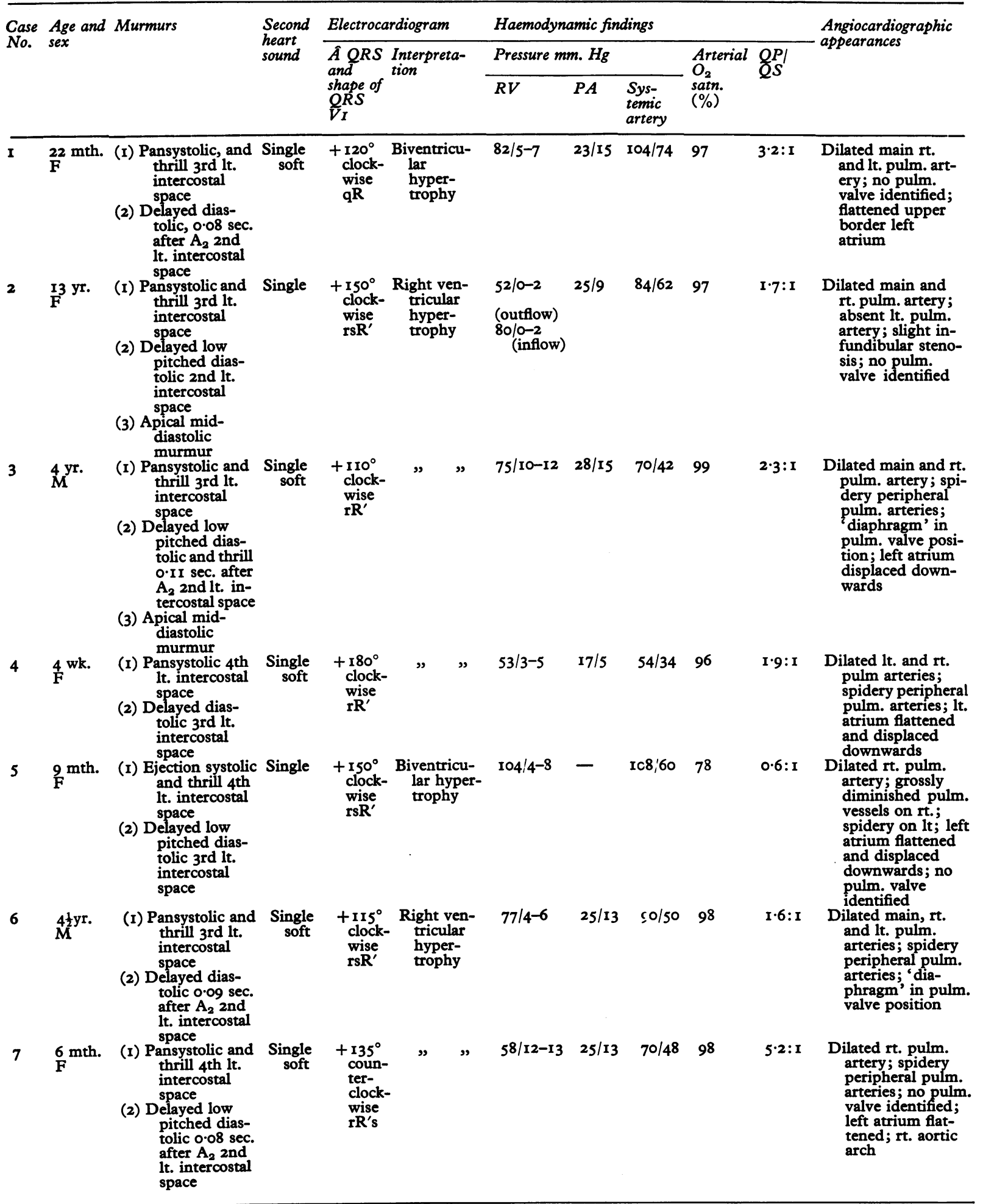


to-left shunt, had an ejection systolic murmur without thrill maximal at the lower left sternal edge. The second heart sound was invariably single and never accentuated. All patients had a decrescendo diastolic murmur best heard at the left sternal edge in the second or third interspace and in one case this was accompanied by a thrill. The murmur was specifically noted to be low pitched in 4 patients and, where phonocardiography was carried out, was found to begin $0.08-0.1 \mathrm{I}$ sec. after the aortic valve closure sound $\left(A_{2}\right)$ which terminated the systolic murmur (Fig. I). This interval did not vary with respiration. The diastolic murmur began with a brief crescendo and no pulmonary valve closure sound $\left(\mathbf{P}_{2}\right)$ was recorded. In 2 patients (Cases 2 and 3 ) there was an apical mid-diastolic murmur, the pulmonary/systemic flow ratios in these two patients being $1 \cdot 7$ and $2 \cdot 3: r$. No ejection sounds were heard or shown phonocardiographically.

Electrocardiographic findings were notably uniform. All had right axis deviation and right ventricular hypertrophy. Cases I and 5 also had left ventricular hypertrophy. In every patient save one (Case 7) the frontal QRS

FIG. I Phonocardiogram of Case 3. Interval between time markers $=0.04 \mathrm{sec}$. PSM, pansystolic murmur; DM, diastolic murmur; $P A H F$, pulmonary area high frequency; $L S E$, lower left sternal edge; $C A R$, indirect carotid pulse; $A_{2}$, aortic closure sound.

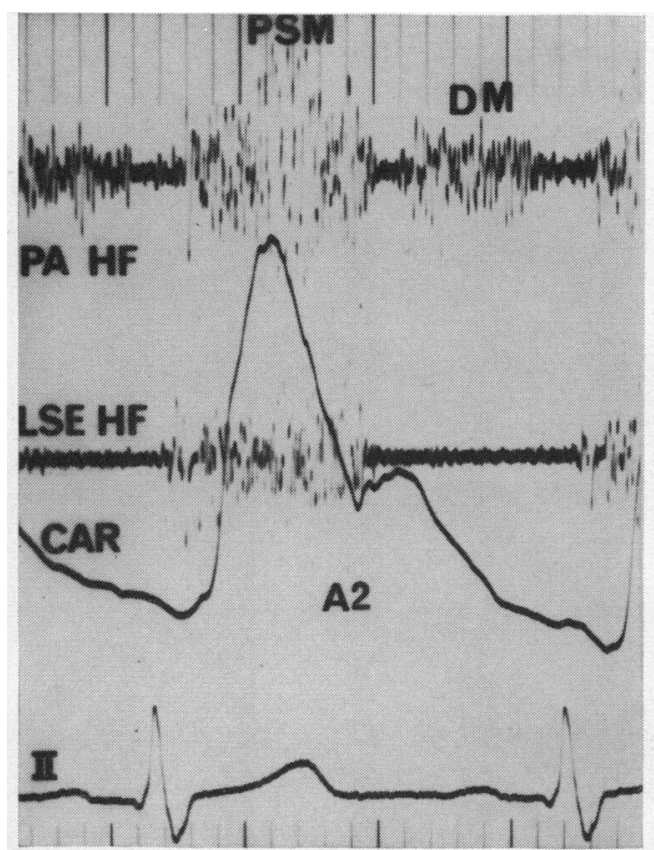

loop was clockwise. Four of the seven patients showed an rsR' pattern in VI, with a normal QRS duration.

Plain chest radiography revealed cardiothoracic ratios in excess of 0.5 in every case save one (Case 2). In three (Cases 3, 6, and 7), there was some prominence of the right cardiac border suggestive of right atrial enlargement. In Case 2 the heart and mediastinum were displaced conspicuously to the left. This patient was subsequently shown to have an absent left pulmonary artery. In 5 patients (Cases 3-7) there was considerable enlargement of the main left or right pulmonary arteries, or any combination thereof (Fig. 2), though in 2 infants the nature of the abnormal hilar shadows was only recognized after angiography. In 2 patients subsequently shown to have aneurysmal dilatation of the right pulmonary artery, this could not have been diagnosed from plain $x$-ray. One (Case I) was aged 22 months, and in the other (Case 2) displacement of the mediastinum to the left had brought the dilated region of the right pulmonary artery anterior to the spine, thus

FIG. $26 \mathrm{ft}$. plain chest x-ray of Case 6. The transverse diameter of the heart is increased. The right pulmonary artery is somewhat enlarged, whereas the left pulmonary artery is aneurysmally dilated. The peripheral pulmonary vasculature is within normal limits.

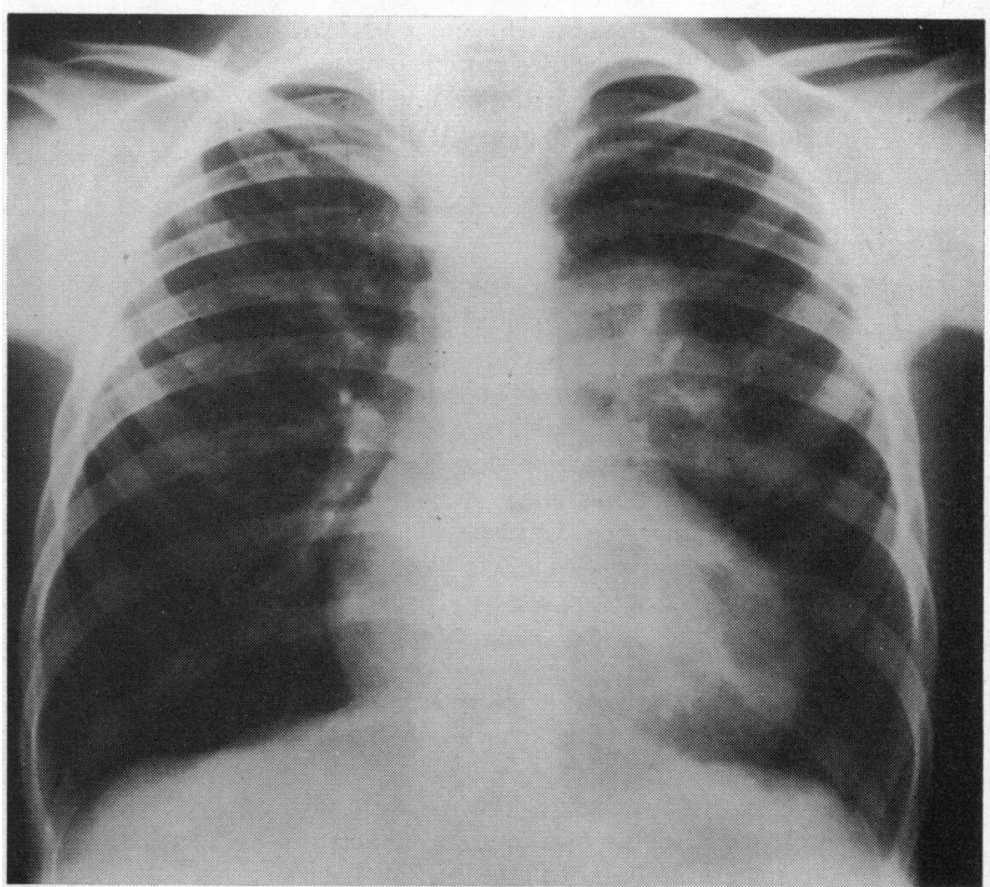


obscuring it. Despite over-all left-to-right shunts in all but one patient the peripheral pulmonary vasculature never appeared increased and in two patients (Cases 4 and 6) (with pulmonary/systemic flow ratios of $I \cdot 9$ and I.6:I) the peripheral lung fields appeared oligaemic. The only patient with a right-toleft intracardiac shunt showed normal vascularity on the left and extreme oligaemia on the right.

\section{Haemodynamic investigations}

All patients were studied by cardiac catheterization and right ventricular angiocardiography. All showed significant rises in oxygen saturation at right ventricular level. In Case 5 the aorta was entered from the right ventricle and the pulmonary artery could not be entered. Right atrial pressures were at the upper limit of normal in 6 patients, the ' $a$ ' wave always being dominant, and in one patient (Case 7) there was a 13 mm. ' $a$ ' wave. Right ventricular systolic pressure was at least 75 per cent of systemic systolic pressure in every case. The right ventricular end-diastolic pressure varied from 2 to $13 \mathrm{~mm}$. $\mathrm{Hg}$. In 3 patients (Cases 3, 4, and 7) there was equalization of right ventricular and pulmonary artery pressures at end-diastole. In 3 (Cases 1,2 , and 6) there were significant systolic and diastolic gradients at the same point in the right ventricular outflow tract. One patient (Case 2) had two right ventricular outflow tract systolic gradients. Systemic arterial desaturation was only present in one patient (Case 5) who was therefore presumed to have a bidirectional shunt at ventricular level. In the remainder there was an over-all left-toright shunt.

\section{Angiocardiography}

Contrast medium injected into the right ventricle crossed a ventricular septal defect to enter the aorta more or less simultaneously with the pulmonary artery in 4 patients (Cases I, 2, 5, and 7), though only one of these patients had an oximetrically demonstrated right-to-left shunt. Infundibular stenosis was only shown in one patient (Case 2).

The pulmonary valve was never seen, but in Cases 3 and 6 there appeared to be a flat, narrow 'diaphragm' in the pulmonary valve position (Fig. 3). This was not domed, as is characteristic of pulmonary valve stenosis, and there was no suggestion of a jet through the centre of the diaphragm.

In every case there was gross abnormality of the appearance of the main pulmonary vessels, ranging from aneurysmal dilatation of the

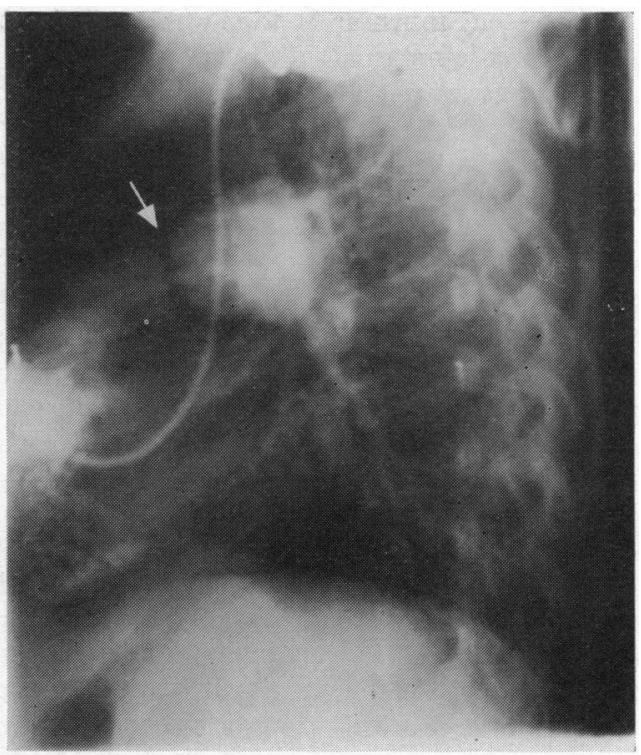

FIG. 3 Selective right ventricular angiocardiogram in Case 6 (lateral projection). A flat diaphragm in the pulmonary valve position is seen, indicated by the white arrow. There is considerable dilatation of the pulmonary artery beyond this, and no infundibular stenosis is seen.

FIG. 4 Selective right ventricular angiocardiogram in Case 4 (frontal projection). The left and right pulmonary arteries are aneurysmally dilated, and there is an abrupt alteration in calibre between those vessels and their immediate branches. 


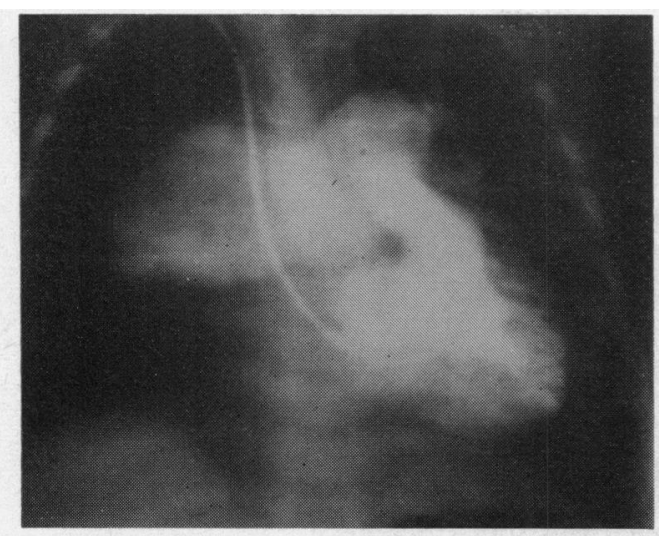

FIG. 5 Selective right ventricular angiocardiogram (frontal projection) in Case 5. The right pulmonary artery is aneurysmally dilated and there is no opacification of the lung beyond $i t$. The left pulmonary artery is less dilated and the vasculature of the left lung is more normal.

main, right, and left pulmonary arteries to apparent involvement of only the right pulmonary artery, which was none the less enormously enlarged. Even more striking than the enlargement of the main pulmonary arteries was the abrupt transition between their calibre and that of the vessels immediately arising from them, which were narrow by comparison (Fig. 4).

Two patients showed gross disparity between the vascularity of the two lungs. In Case 2 the left pulmonary artery was absent and in Case 5 (Fig. 5), though there was an aneurysm of the right pulmonary artery, the peripheral pulmonary vessels did not appear to opacify at any stage.

The left atrial anatomy was distorted in 5 out of the 6 cases in which it could be clearly seen, presumably as a result of the dilatation of the right pulmonary artery, which caused flattening or concavity of the superior left atrial border as well as downward displacement of the whole left atrium in 3 cases (Fig. 6). In one instance the left atrium was displaced so far downwards that it lay in the same horizontal plane as the left ventricle.

Aortography excluded aortic incompetence and persistent ductus arteriosus in 4 patients (Cases 2, 3, 6, and 7), and the latter diagnosis was excluded in Case I by left atrial angiocardiography.

\section{Operative and post-mortem findings}

These were available in three instances. Case 4 contracted a chest infection at the age of 6 months and died from uncontrollable heart

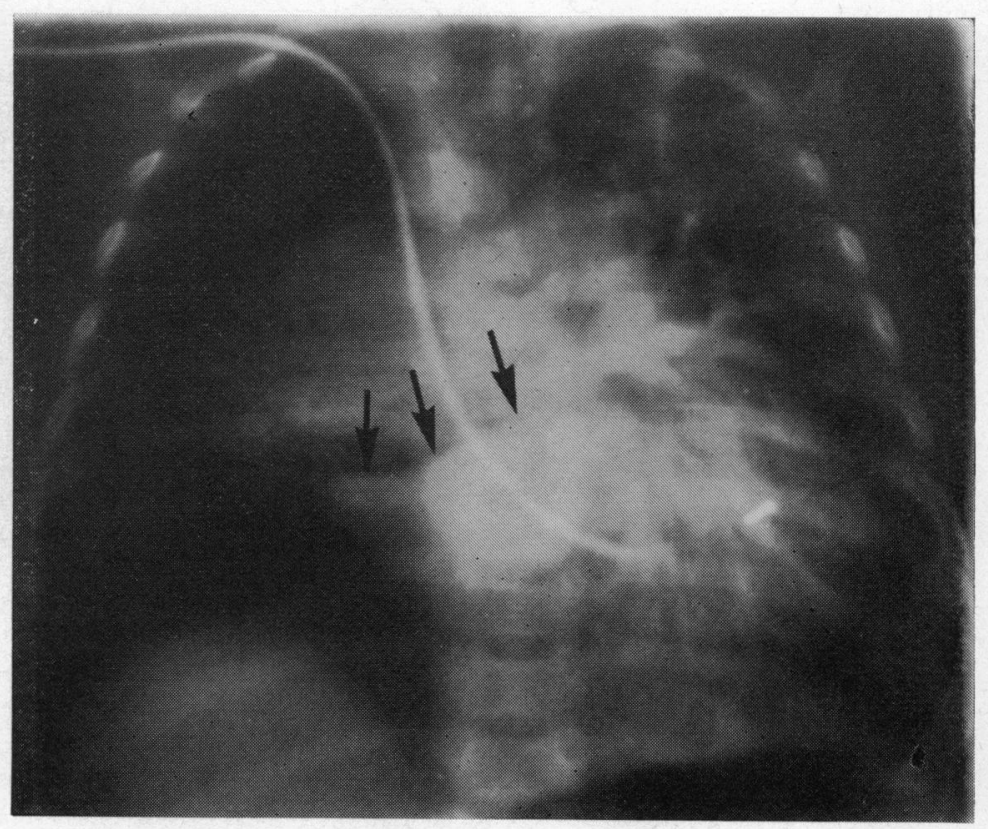

FIG. 6 Selective right ventricular angiocardiogram in Case 5. Contrast medium is returning to the left pulmonary veins. The right pulmonary veins are not seen. The superior margin of the left atrium (indicated by black arrows) is displaced downwards and distorted by the aneurysmal right pulmonary artery. The aortic arch is right sided.

failure. Necropsy was limited to the heart. There was considerable dilatation of both ventricles and the muscle of the right ventricle was moderately hypertrophied. The pulmonary valve was represented by a rudimentary fringe of tissue with no subdivision into cusps (Fig. 7). The valve ring was narrowed and the pulmonary artery above was greatly dilated. There was a $0.8 \mathrm{~cm}$. ventricular septal defect in the infracristal position and the crista supraventricularis was moderately hypertrophied. The main site of right ventricular outflow tract obstruction was the pulmonary valve ring. There was no aortic override and the relationships of the atrioventricular and semilunar 'valves' were normal.

Case 6 was operated on at the age of 7 years. The pulmonary artery was found to be greatly enlarged, and there was a diastolic thrill in the right ventricular outflow tract in addition to a systolic thrill over the right ventricle. On opening the right ventricle, the crista supraventricularis was found to be hypertrophied. The pulmonary valve was rudimentary. There was a $2 \times 1 \mathrm{~cm}$. infracristal ventricular septal defect. The defect was closed with a Dacron patch and infundibular resection per- 


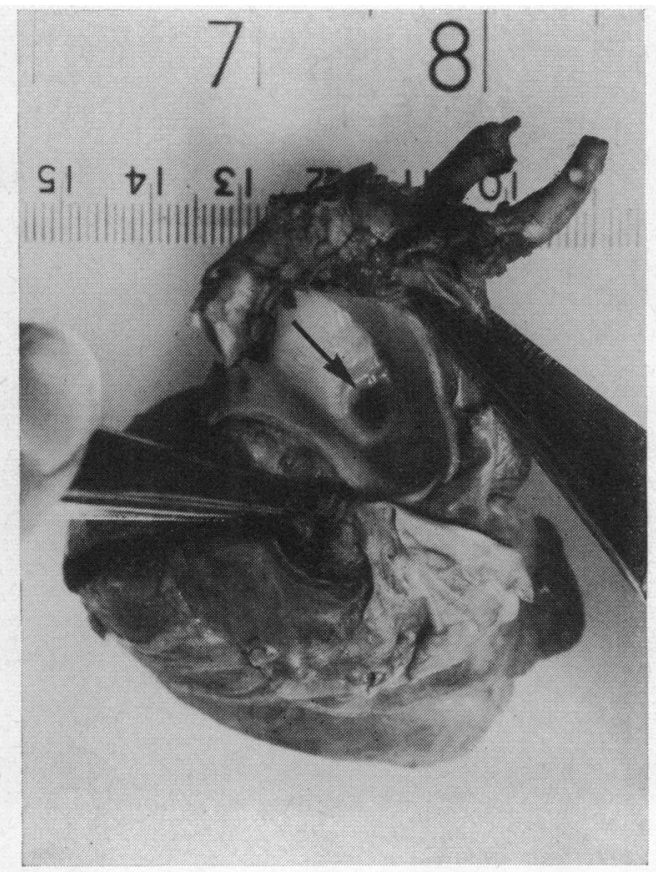

FIG. 7 Post-mortem heart of Case 4. The black arrow indicates the pulmonary valve ring. The pulmonary valve consists of a rudimentary fringe of tissue only. The pulmonary artery is dilated and the aortic arch is seen curving round it.

formed. This resulted in a fall of right ventricular pressure from $125 / 12$ before operation to $48 / 12 \mathrm{~mm}$. $\mathrm{Hg}$ after operation, while the pulmonary artery pressure remained at $28 / 18$ $\mathrm{mm} . \mathrm{Hg}$. In this patient, therefore, pulmonary stenosis appeared to be mainly at infundibular level. Despite resuscitative measures, the patient died soon after operation. Necropsy confirmed the above findings, demonstrating that the right ventricular wall thickness was thrice normal, and showed that the lungs were normal apart from partial collapse.

Case 3 underwent operation at 5 years of age. The main and right pulmonary arteries were aneurysmally dilated, whereas the left pulmonary artery was normal in diameter. The sole pressure gradient in the right ventricular outflow tract was at the level of the valve ring, which was smaller than normal, the pulmonary valve being represented by a ring of fibrous tissue about $2 \mathrm{~mm}$. in depth with no cusps. There was a large infracristal ventricular septal defect and the crista supraventricularis was hypertrophied. The septal defect was closed with a Teflon patch and a portion of the hypertrophied crista was excised. This procedure did not significantly reduce the outflow tract gradient. Death occurred two days later.

Post-mortem examination of the heart confirmed the above findings. Both ventricles were hypertrophied. The right lung appeared macroscopically normal but the left lung lacked a fissure. Bronchography showed a normal bronchial pattern of the left lung. Injection of the veins of the left lung revealed an abnormal pattern, with too few large tributaries draining into axial veins, suggesting abnormal antenatal development of blood vessels within the lung.

Microscopically the pulmonary valve ring was composed of collagen and some muscle. The left pulmonary artery and the peripheral intrapulmonary arteries in both lungs showed changes similar to those found in patients with pulmonary hypertensive ventricular septal defects (Heath and Edwards, 1958; Wagenvoort et al., 1967). The media of the left pulmonary artery, which was of normal calibre, was of aortic type with concentric rings of elastic laminae and the small arteries running with distal bronchioli were enlarged, with abnormally thick walls. Muscular arteries extended into the acinus, which would not be expected at this age (Hislop, 1969; Davies, 1969). The structure of the dilated main and right pulmonary arteries was different from that of the left. Here the media was in two zones, a band of aortic type at the intimal edge, and external to this a layer of fragmented elastic fibres among collagen and muscle. The media was not demarcated by an external elastic lamina. The adventitia contained more elastic fibres than are usually found.

\section{Discussion}

These findings, together with those of other investigators (Miller et al., 1962; Soulié et al., 1967), suggest that the combination of a pansystolic murmur at the left sternal border, a single, unaccentuated second sound, and a low-pitched crescendo-decrescendo murmur in the pulmonary area starting about 0.1 sec. after the second heart sound is pathognomonic of ventricular septal defect with absent pulmonary valve.

The diastolic murmur in this condition differs from that found in pulmonary incompetence without pulmonary hypertension or intracardiac shunt in that it starts later. Thus, Bousvaros and Deuchar (I96I) found that the murmur of isolated pulmonary regurgitation begins $0.02-0.03 \mathrm{sec}$. after aortic valve closure, while in the cases reported here it began $0.08-$ 0. II sec. after aortic valve closure. This additional delay may reflect extra prolonga- 
tion of right ventricular ejection time by the left-to-right shunt at ventricular level.

Though pulmonary artery dilatation can give rise to a pulmonary ejection sound (Leatham and Vogelpoel, 1954) it was of interest that none of the patients reported here had such ejection sounds despite considerable pulmonary artery dilatation. The absence of an ejection sound may be the result of absence of the pulmonary valve; however, ejection sounds have been recorded twice in this condition (Elliott et al., 1962; Ruttenberg et al., 1964).

The absence of the pulmonary valve in this syndrome must result in pulmonary regurgitation as manifested by the diastolic murmur already described. In isolated pulmonary regurgitation there is equalization of the right ventricular and pulmonary artery pressures at end-diastole (Collins, Braunwald, and Morrow, 1960). However in 3 out of 6 patients presented here, these pressures differed by at least $7 \mathrm{~mm}$. $\mathrm{Hg}$. This finding has been reported elsewhere (Campeau et al., 1961; D'Cruz et al., 1964) and may be due to obstruction to regurgitant flow from the pulmonary artery.

Accurate identification of the site of right ventricular outflow tract obstruction may be difficult. Miller et al. (1962) state that in their experience obstruction was at infundibular level, whereas Ruttenberg et al. (1964) favoured the valve ring as the site of stenosis. In this series, obstruction has been shown at operation or necropsy to exist at infundibular level or at valve level. Withdrawal pressure traces from pulmonary artery to right ventricle may not always distinguish these two entities, and in Case 6, where infundibular resection alone almost completely abolished right ventricular outflow tract obstruction, angiocardiographic and haemodynamic data had wrongly identified the stenosis as being at 'valve' level.

The right ventricular angiographic features of this syndrome are striking. We have not seen the gross dilatation of the main pulmonary trunk and right and left branches and the abrupt transition in calibre between the main trunks and their immediate branches in any other condition. Equally striking was the compression and downward displacement of the left atrium by the dilated right pulmonary artery. This radiological sign has not been noted before, though compression of the left main bronchus by the dilated pulmonary artery is recorded (Miller et al., 1962; D'Cruz et al., 1964). Other associated features of this series are absence of the left pulmonary artery (Case 2), absence of visible opacification of the right lung from an aneurysmal right pulmonary artery (Case 5), and absence of the left lung fissure (Case 3).

The difference in histological appearance between the dilated main and right pulmonary arteries and the macroscopically normal left pulmonary artery seen in Case 3 has not been described before. Persistence of aortic type media was reported by Smith et al. (1959) in the dilated main pulmonary artery, whereas in our patient it was only seen in the left pulmonary artery, which was not enlarged. The histological appearance of the main and right pulmonary arteries was similar to that reported by D'Cruz et al. (I964). The presence of medial hypertrophy of the pulmonary arteries in both lungs in the absence of pulmonary hypertension casts some doubt upon the usually assumed relation between hypertrophy and hypertension in congenital heart lesions with increased pulmonary flow (Edwards, 1957; Wagenvoort et al., 1967).

We wish to thank Dr. R. V. Gibson and Dr. M. C. Joseph for allowing us to publish details of their patients. Special thanks are due to Dr. A. A. Hislop who prepared the histological report on Case 3.

\section{References}

Bousvaros, G. A., and Deuchar, D. C. (196I). The murmur of pulmonary regurgitation which is not associated with pulmonary hypertension. Lancet, 2, 962.

Campeau, L. A., Gilbert, G., and Aerichide, N. (I96I). Absence of the pulmonary valve. Report of two cases associated with other congenital lesions. American fournal of Cardiology, 8, I 13.

$\longrightarrow$, Ruble, P. E., and Cooksey, W. B. (1957). Congenital absence of the pulmonary valve. Circulation, 15, 397.

Childers, R. W., and McCrea, P. C. (1964). Absence of the pulmonary valve. A case occurring in the Marfan syndrome. Circulation, 29, 598.

Collins, N. P., Braunwald, E., and Morrow, A. G. (I960). Isolated congenital pulmonic valvular regurgitation: diagnosis by cardiac catheterization and angiocardiography. American fournal of Medicine, $28,159$.

Davies, G. M. (1969) Lung damage, hypoplasia and right ventricular hypertrophy in cystic fibrosis. In Proceedings of the Fifth International Cystic Fibrosis Conference, p. 350. Ed. by D. Lawson. Cystic Fibrosis Research Trust, London.

D'Cruz, I. A., Lendrum, B. L., and Novak, G. (1964). Congenital absence of the pulmonary valve. American Heart fournal, 68, 728.

Edwards, J. E. (1957). Functional pathology of the pulmonary vascular tree in congenital cardiac disease. Circulation, 15, 164 .

Elliott, L. P., Shanklin, D. R., and Schiebler, G. L. (I962). Congenital insufficiency of the pulmonary valve with a ventricular septal defect. Diseases of the Chest, 42, 534.

Gasul, B. M., Buenger, R. F., Julian, O. C., and Trueheart, R. E. (I96I). Clinical pathologic conference. American Heart fournal, 6r, 126.

Heath, D., and Edwards, J. E. (1958). The pathology of hypertensive pulmonary vascular disease. A 
description of six grades of structural changes in the pulmonary arteries with special reference to congenital cardiac septal defects. Circulation, 18, 533.

Hislop, A. 1969). The non-muscular phase of the pulmonary circulation in the child. In Proceedings of the Fifth International Cystic Fibrosis Conference, p. 340. Ed. by D. Lawson. Cystic Fibrosis Research Trust, London.

Lavenne, F., Tyberghein, J., Brasseur, L., and Meersseman, F. (I954). Complexe d'Eisenmenger avec insuffisance pulmonaire par absence de valvules. Acta Cardiologica, 9, 249.

Leatham, A., and Vogelpoel, L. (1954). The early systolic sound in dilatation of the pulmonary artery. British Heart fournal, 16, 2 I.

Miller, R. A., Lev, M., and Paul, M. H. (1962). Congenital absence of the pulmonary valve. Circulation, 26, 266.

Onesti, S. J., and Harned, H. S., Jr. (1958). Absence of the pulmonary valve associated with ventricular septal defect. American fournal of Cardiology, 2,496.
Ruttenberg, H. D., Carey, L. S., Adams, P., Jr., and Edwards, J. E. (1964). Absence of the pulmonary valve in the tetralogy of Fallot. American fournal of Roentgenology, Radium Therapy, and Nuclear Medicine, 91, 500.

Smith, R. D., DuShane, J. W., and Edwards, J. E. (1959). Congenital insufficiency of the pulmonary valve. Circulation, 20, 554.

Soulié, P., Vernant, P., Sterba, S., Bouchard, F., Albou, E., Lanfranchi, J., and Letac, B. (1967). Insuffisance pulmonaire congénitale et communication interventriculaire (étude clinique, hémodynamique et angiocardiographique). Archives des Maladies du Coeur et des Vaisseaux, 60, 172.

Venables, A. W. (1962). Absence of the pulmonary valve with ventricular septal defect. British Heart Fournal, 24, 293.

Wagenvoort, C. A., Nauta, J., van der Schaar, P. J., Weeda, H. W. H., and Wagenvoort, N. (I967). Effect of flow and pressure on pulmonary vessels. Circulation, 35, 1028 . 